\title{
Investigating the associations between productive housework activities, sleep hours and self-reported health among elderly men and women in western industrialised countries
}

\author{
Nicholas Kofi Adjei ${ }^{1,2^{*}}$ and Tilman Brand ${ }^{1}$
}

\begin{abstract}
Background: After retirement, elderly men and women allocate more time to housework activities, compared to working-age adults. Nonetheless, sleep constitutes the lengthiest time use activity among the elderly, but there has not been any study on the associations between time spent on housework activities, sleep duration and selfreported health among the older population. This study not only examined individual associations between selfreported health and both housework activities and sleep duration, but it also explored self-reported health by the interaction effect between housework activities and sleep duration separately for men and women.

Methods: Pooled data from the Multinational Time Use Study (MTUS) on 15,333 men and 20,907 women from Germany, Italy, Spain, UK, France, the Netherlands and the US were analysed. Multiple binary logistic regression models were used to examine the associations between three broad categories of housework activities ((1) cooking, cleaning and shopping, (2) gardening and maintenance; (3) childcare) and health. We further investigated the extent to which total housework hours and sleep duration were associated with self-reported health for men and women separately.

Results: We found a positive association between time devoted to housework activities, total housework and health status among elderly men and women. Compared to those who spent 1 to $3 \mathrm{~h}$ on total productive housework, elderly people who spent $>3$ to $6 \mathrm{~h} /$ day had higher odds of reporting good health $(\mathrm{OR}=1.25 ; 95 \% \mathrm{Cl}=1.14-1.37$ among men and $\mathrm{OR}=1.10 ; 95 \% \mathrm{Cl}=1.01-1.20$ among women). Both short $(<7 \mathrm{~h})$ and long $(>8 \mathrm{~h}$ ) sleep duration were negatively associated with health for both genders. However, the interactive associations between total productive housework, sleep duration, and self-reported health varied among men and women. Among women, long hours of housework combined with either short or long sleep was negatively associated with health.

Conclusions: Although time allocation to housework activities may be beneficial to the health among both genders, elderly women have higher odds of reporting poor health when more time is devoted total housework combined with either short or long sleep duration.
\end{abstract}

Keywords: Self-reported health, Gender, Elderly, Sleep duration, Housework activities

\footnotetext{
* Correspondence: adjei@uni-bremen.de

${ }^{1}$ Department of Prevention and Evaluation, Leibniz Institute for Prevention

Research and Epidemiology - BIPS, Germany, Unit Social Epidemiology,

Achterstrasse 30, D-28359 Bremen, Germany

${ }^{2}$ Health Sciences Bremen, University of Bremen, Bremen, Germany
} 


\section{Background}

Due to the increase in life expectancy among older adults, time spent in retirement has increased remarkably [1]. In fact, the retirement of an individual affects the distribution of allocated time to the various task of life. A plethora of literature has examined how elderly men and women spend their time after retirement. Most of the related literature that examined post-retirement time use showed that elderly men and women are more involved in social roles and activities such as voluntary work [2-4], leisure activities [5, 6], grandparenting $[7,8]$ and household activities $[6,9]$, than their younger counterparts [9-11].

Household activities are part of the daily lives of older people. These activities have become their main "productive work" after retirement [12]. Using longitudinal data, Szinovacz [13] found that retirees devoted more time to housework activities than their working spouses. However, evidence suggests that gender inequality in the division of household labor largely persists in highincome societies even after retirement [13, 14]. Most studies confirm that elderly women spend more time on housework activities than men [14-16], although time allocated to housework activities among men has increased over recent years [15]. Again, women typically perform routine, repetitive tasks such washing clothes, cooking and cleaning house $[17,18]$, while men are responsible for occasional tasks such as household repair works, vehicle maintenance and yard work [17, 18]. It has been suggested that this inequitable division of housework is one of the factors that contribute to the observed adverse health differences among men and women including psychological distress [19] and depressive symptoms [20]. These adverse health outcomes are stronger for women than men in their prime working age [21]. Thus, gendered work-life imbalance could be a contributing factor for health inequalities, where women are more likely than men to report poorer health [19]. Although the gendered distribution of housework seems to be correlated with low psychological well-being and poor health among women, there is some evidence that suggests housework may have a positive impact on physical health among elderly men and women [14, 22].

Nonetheless, an important aspect of daily time use activities among older men and women is sleep. Sleep is one of the most important determinants of health [23]. Thus, the duration and quality of sleep have significant health consequences for children, adults and the elderly. Among the elderly, sleep constitutes the lengthiest daily activity [24]. This is expected because the increasing prevalence of health conditions at older age restricts time allocation for other daily activities [6]. Time devoted to sleep is therefore crucial because it has been shown to be correlated with health among older adults.
Among adults, short sleep has been found to be associated with some adverse health outcomes including cardiovascular disease and obesity [25]. Conversely, long sleep duration has been linked with increased risk of mortality and morbidity [23].

Time resources are limited within $24 \mathrm{~h}$ or $1440 \mathrm{~min}$ in a day. Therefore, within this period, time devoted to a particular activity influences time allocation to other daily activities. For example, more time allocation to housework may decrease the amount of time devoted to sleep or other time use activities such as leisure.

To our knowledge, only one study has examined the effect of various housework activities on health among older adults [26]. Moreover, the gender-specific interactive effects of time spent on housework and sleep duration on self-reported health have yet to be investigated among the elderly. Accordingly, this study seeks to explore the relationship between housework activities, total housework and sleep on self-reported health among the elderly in high-income countries. The following two questions will be addressed:

1) How does time spent on housework activities impact the health among the elderly? To what extent do these effects vary by gender?

2) To what extent is the association between housework activities and health moderated by sleep hours among men and women?

\section{Methods}

Data

Data came from the Multinational Time Use Study (MTUS, version W53), a cross-national harmonized and comparative time-use database. The Centre for Time Use Research at the University of Oxford organized and collated this data, which was a collection of national randomly-sampled time-use surveys conducted by institutions in 25 countries [27]. This data set contains information on time allocation to various daily tasks, as well as socio-economic and demographic background information of the respective diarist. Diaries were self-administered, followed by a personal visit in most countries. In the interviews, individual participants reported the total time spent per day on 41 activities in 5, 10 or 15-min intervals [27], during a randomly assigned day in a week in Spain, Italy, Germany France and the US or two days (weekday and weekend) in the UK. In the Netherlands, individuals report their activities throughout the $24 \mathrm{~h}$ of the day for seven consecutive days. We excluded individuals whose diaries did not sum up to $1440 \mathrm{~min}$ ( $24 \mathrm{~h}$ ) of activities during the day. Only primary or "main" activities were included in this analysis. Information on secondary activities (activities done while multitasking) were not captured. After considering the minimum retirement age in most EU countries., 
we limited our sample to individuals who were 65 years and above. For the selection of countries, we selected countries that incorporate health and wellbeing measures into their diary collections. The countries used for the final analysis after these exclusions were the United Kingdom (survey year: 2000; response rate: 45\%), the United States (survey year: 2003, response rate: 57\%), Spain (survey year: 2002; response rate: 64\%), Italy (survey year: 2002; response rate: 92\%), Germany (survey year: 2001; response rate: 96\%), France (survey year: 1998, response rate: $88 \%$ ) and the Netherlands (survey year: 2000; response rate: 25\%).

\section{Independent variables}

Time spent on housework activities and sleep were the two independent variables used for this study. Sleep time and time allocated to housework activities were directly estimated from the data. Because it is not easy to identify productive household activities in time use research, we used the "third party" criterion to identify and select these activities. This approach is widely used in the literature in defining productive household activities [28]. By this criterion, "if an activity is of such a character that might be delegated to a paid worker, then that activity shall be deemed productive" [29]. In other words, this comprises housework that people can pay others to perform for them. Hence, activities such as cooking, gardening, washing, maintenance, laundry, grocery shopping and childcare were considered as productive housework activities. In this current study, we focused on three broad categories of housework activities, in line with Wen et al. [26]:

- cooking, cleaning and shopping

- gardening and maintenance

- childcare

Each category of time use activity was measured in minutes per day. Total housework hours were measured in hours per day. Sleep hours or duration was defined as the total amount of time devoted to sleep. This encompasses all forms of sleep (including daytime sleep and naps). Sleep hours were classified into three categories, i.e., $<7 \mathrm{~h}$ (short sleep duration), 7-8 h (optimal sleep duration), and $>8 \mathrm{~h}$ (long sleep duration), based on existing cut-offs in epidemiologic studies [30].

\section{Dependent variable}

The dependent variable was self-reported health. In the time-use survey, the question posed to the diarist was "How is your health in general; would you say that it is ...?" response options: zero (poor) to three (very good). We categorized the responses into poor (poor or fair) and good (good or very good) [14]. Selfreported health has been shown to be a reliable and accurate measure of current health status [31, 32].

\section{Covariates}

Covariates included in the analyses were age, education (less than secondary education, completed secondary education and above secondary education), housing tenure (owner-occupier, renting), employment status (not working for pay, currently in paid employment), household size $(1,2,3+)$ and car ownership (no car, one car and two or more cars).

\section{Statistical analysis}

The first part of the analysis was primarily descriptive, where information on distributional characteristics of all variables including the mean time allocated to the various productive housework activities was provided. In the second part of the analysis, we applied binary logistic regression to model the association between self-reported health and each of the three broad housework categories, total housework and sleep hours. The multivariate regression models included other time use activities (paid work, active leisure, passive leisure and personal activities, see Additional file 1: Table S2). In the third part, we examined the combined association of total productive housework hours and sleep duration (short sleep duration, optimal sleep duration and long sleep duration) on selfreported health. Here, we investigated twelve combinations as follows: four groups of total productive housework hours (housework <1 h/day, housework 1 to $3 \mathrm{~h} /$ day, housework $>3$ to $6 \mathrm{~h} /$ day, housework $>6 \mathrm{~h} /$ day $) \times$ three groups of sleep hours (sleep $<7 \mathrm{~h} /$ day, sleep $>7$ to $8 \mathrm{~h} /$ day, sleep $>8 \mathrm{~h} /$ day). The $>7$ to $8 \mathrm{~h} /$ day sleep duration and 1 to $3 \mathrm{~h} /$ day time spent on productive housework categories were chosen as the reference. The analyses were done separately for men and women. All statistical analyses were performed in STATA version 14 [33].

\section{Results}

\section{Descriptive statistics}

The descriptive statistics for respondents stratified by gender are shown in Table 1.

Women in the study were slightly older than men. The mean age of women was 73.2 years and for men 72.4 years. Men had higher educational attainment than women. About $20.3 \%$ of elderly men and $13.3 \%$ of women reported having a tertiary education. Elderly men were more likely to own a house than women (77.5\% vs $73.2 \%)$. Regarding employment status, about $9.0 \%$ of older men were in paid employment, compared to $4.7 \%$ of women. The average number of people in the household was similar for both men and women (approximately 2 members).

Gender differences were also found in time allocation to productive housework activities. Older men and women both allocated more time to cleaning and cooking than to occasional task such as gardening and maintenance. 
Table 1 General description of the study sample (in percentages, means and SD), men and women

\begin{tabular}{|c|c|c|c|c|}
\hline & \multicolumn{2}{|c|}{ Men $(15,333)$} & \multicolumn{2}{|c|}{ Women $(20,907)$} \\
\hline & Mean / \% & SD & Mean / \% & SD \\
\hline \multicolumn{5}{|l|}{$\begin{array}{l}\text { Sociodemographic and } \\
\text { economic factors }\end{array}$} \\
\hline Age & 72.39 & 5.06 & 73.19 & 5.21 \\
\hline $65-69$ & $35.7 \%$ & & $31.0 \%$ & \\
\hline 70-74 & $28.3 \%$ & & $26.3 \%$ & \\
\hline $75-79$ & $20.0 \%$ & & $20.7 \%$ & \\
\hline $80+$ & $16.1 \%$ & & $22.0 \%$ & \\
\hline \multicolumn{5}{|l|}{ Education } \\
\hline Incomplete Sec. or less & $49.6 \%$ & & $58.3 \%$ & \\
\hline Secondary completed & $30.1 \%$ & & $28.3 \%$ & \\
\hline Tertiary Completed or above & $20.3 \%$ & & $13.3 \%$ & \\
\hline \multicolumn{5}{|l|}{ Land tenure } \\
\hline Renting & $22.5 \%$ & & $26.8 \%$ & \\
\hline Owner occupier & $77.5 \%$ & & $73.2 \%$ & \\
\hline \multicolumn{5}{|l|}{ Employment Status } \\
\hline Not working for pay & $91.0 \%$ & & $95.3 \%$ & \\
\hline Currently in paid employment & $9.0 \%$ & & $4.7 \%$ & \\
\hline Household size & 2.20 & 1.02 & 1.89 & 1.08 \\
\hline 1 member & $18.2 \%$ & & $41.6 \%$ & \\
\hline 2 members & $59.1 \%$ & & $41.3 \%$ & \\
\hline 3+ members & $22.8 \%$ & & $17.1 \%$ & \\
\hline \multicolumn{5}{|l|}{ Time use Activity } \\
\hline $\begin{array}{l}\text { Cleaning, cooking \& shopping } \\
\text { mins/day }\end{array}$ & 84.74 & 97.02 & 217.88 & 139.45 \\
\hline $0 \mathrm{~min}$ & $27.4 \%$ & & $7.2 \%$ & \\
\hline$>0$ to 60 & $27.4 \%$ & & $9.7 \%$ & \\
\hline$>60$ to 120 & $18.2 \%$ & & $11.4 \%$ & \\
\hline$>120$ & $26.9 \%$ & & $71.8 \%$ & \\
\hline $\begin{array}{l}\text { Gardening and maintenance } \\
\text { mins/day }\end{array}$ & 68.56 & 109.37 & 38.54 & 77.43 \\
\hline $0 \mathrm{~min}$ & $50.4 \%$ & & $59.2 \%$ & \\
\hline$>0$ to 60 & $17.4 \%$ & & $21.4 \%$ & \\
\hline$>60$ to 120 & $11.0 \%$ & & $9.3 \%$ & \\
\hline$>120$ & $21.2 \%$ & & $10.2 \%$ & \\
\hline Childcare mins/day & 1.41 & 15.02 & 2.07 & 19.59 \\
\hline $0 \mathrm{~min}$ & $98.3 \%$ & & $97.7 \%$ & \\
\hline$>0$ to 60 & $1.0 \%$ & & $1.2 \%$ & \\
\hline$>60$ to 120 & $0.3 \%$ & & $0.5 \%$ & \\
\hline$>120$ & $0.4 \%$ & & $0.5 \%$ & \\
\hline Total Housework hours/day & 3.09 & 2.65 & 4.72 & 2.71 \\
\hline Less than 1 & $26.4 \%$ & & $10.0 \%$ & \\
\hline 1 to 3 & $27.1 \%$ & & $16.4 \%$ & \\
\hline
\end{tabular}

Table 1 General description of the study sample (in percentages, means and SD), men and women (Continued)

\begin{tabular}{|c|c|c|c|c|}
\hline & \multicolumn{2}{|c|}{ Men $(15,333)$} & \multicolumn{2}{|c|}{ Women $(20,907)$} \\
\hline & Mean / \% & SD & Mean / \% & SD \\
\hline$>3$ to 6 & $31.9 \%$ & & $42.8 \%$ & \\
\hline$>6$ & $14.7 \%$ & & $30.8 \%$ & \\
\hline Sleep hours/day & 9.43 & 2.07 & 9.34 & 2.10 \\
\hline less than 7 & $6.7 \%$ & & $6.9 \%$ & \\
\hline$>7$ to 8 & $17.4 \%$ & & $18.2 \%$ & \\
\hline$>8$ & $75.9 \%$ & & $75.0 \%$ & \\
\hline
\end{tabular}

However, men spent remarkably fewer hours on cleaning, cooking and shopping than women $(88.7 \mathrm{~min} /$ day vs $217.9 \mathrm{~min} /$ day). On the other hand, women devoted fewer hours on gardening and maintenance than men $(38.5 \mathrm{~min} /$ day vs $68.6 \mathrm{~min} /$ day). Regarding the time allocation to total housework, women devoted most hours to these activities ( $4.7 \mathrm{~h}$ per day) compared to men ( $3.1 \mathrm{~h}$ per day). A crosscountry comparison in Additional file 2: Table S1 revealed that the most time spent on total housework among elderly women was found in Italy (5.2 h per day) and Germany (5.1 $\mathrm{h}$ per day), while the lowest value was observed in the US ( $4.0 \mathrm{~h}$ per day). In contrast, elderly men in Italy devoted the least time to total housework activities ( $2.7 \mathrm{~h}$ per day), while the most time spent on these activities was found in Germany ( $4.2 \mathrm{~h}$ per day).

Time allocated to sleep hours was similar in both genders. Elderly men and women slept for approximately $9 \mathrm{~h}$ per day (including daytime sleep and naps). Again, we observed that there were no differences in time devoted to sleep hours among men and women within-countries, but there were cross-national variations (Additional file 2: Table S1). For instance, elderly men and women in Spain and France devoted the most time to sleep hours (approximately $10 \mathrm{~h}$ per day), while the average time spent on these activities in the other countries was $1 \mathrm{~h}$ less.

\section{Logistic regression}

The results of the adjusted OR and 95\% CI for the association between the three broad productive housework activities, total housework, sleep hours and the outcome self-reported health are shown in Tables 2 and 3.

Among men and women, we found a positive association between housework activities and self-reported health. However, there were differences in the magnitude of the associations. Time devoted to both routine and repetitive housework activities was significantly associated with good health. We observed that elderly people who spent more than $120 \mathrm{~min} /$ day on cleaning, cooking and shopping activities had higher odds of reporting 
Table 2 Multivariate associations between good self-reported health status and housework, pooled data of 7 countries. Men, women $65+$ years old

\begin{tabular}{|c|c|c|}
\hline Variables & Men & Women \\
\hline & $\mathrm{aOR}(95 \% \mathrm{Cl})$ & aOR $(95 \% \mathrm{Cl})$ \\
\hline \multicolumn{3}{|c|}{ Time use Activities } \\
\hline \multicolumn{3}{|c|}{$\begin{array}{l}\text { Cleaning, cooking \& shopping } \\
\text { mins/day }\end{array}$} \\
\hline 0 min (ref) & 1.00 (reference) & 1.00 (reference) \\
\hline$>0$ to 60 & $1.23(1.12-1.35)^{* *}$ & $1.61(1.38-1.89)^{* *}$ \\
\hline$>60$ to 120 & $1.13(1.02-1.26)^{*}$ & $1.46(1.25-1.70)^{* *}$ \\
\hline$>120$ & $1.58(1.43-1.74)^{* *}$ & $1.48(1.30-1.68)^{* *}$ \\
\hline \multicolumn{3}{|c|}{$\begin{array}{l}\text { Gardening and maintenance } \\
\text { mins/day }\end{array}$} \\
\hline 0 min (ref) & 1.00 (reference) & 1.00 (reference) \\
\hline$>0$ to 60 & $1.27(1.16-1.40)^{* *}$ & $1.31(1.22-1.41)^{* *}$ \\
\hline$>60$ to 120 & $1.40(1.25-1.56)^{* *}$ & $1.43(1.29-1.59)^{* *}$ \\
\hline$>120$ & $1.80(1.64-1.98)^{* *}$ & $1.56(1.41-1.73)^{* *}$ \\
\hline \multicolumn{3}{|c|}{ Childcare mins/day } \\
\hline 0 min (ref) & 1.00 (reference) & 1.00 (reference) \\
\hline$>0$ to 60 & $1.18(0.85-1.65)$ & $1.11(0.85-1.46)$ \\
\hline$>60$ to 120 & $1.60(0.85-3.00)$ & $1.25(0.83-1.87)$ \\
\hline$>120$ & $1.81(1.03-3.20)^{*}$ & $2.46(1.63-3.72)^{* *}$ \\
\hline Pseudo R2 & 0.0815 & 0.1049 \\
\hline Log Likelihood & -9728.2581 & $-12,635.574$ \\
\hline
\end{tabular}

Notes: aOR-adjusted Odd Ratio, ${ }^{* *} p<0.01,{ }^{*} p<0.05$. Cl: confidence interval. Adjusted by age, education, householdsize, land tenure, employment status and other time use activities (active leisure, paid work, passive leisure \& personal activities)

Table 3 Multivariate associations between good self-reported health status, total housework and sleep hours, pooled data of 7 countries. Men, women 65+ years old

\begin{tabular}{lll}
\hline Variables & Men & Women \\
\hline & aOR $(95 \% \mathrm{Cl})$ & $\mathrm{aOR}(95 \% \mathrm{Cl})$ \\
Total housework hours/day & & \\
less than 1 & $0.74(0.67-0.81)^{* *}$ & $0.69(0.60-0.78)^{* *}$ \\
1 to 3 & $1.00($ reference) & 1.00 (reference) \\
$>3$ to 6 & $1.25(1.14-1.37)^{* *}$ & $1.10(1.01-1.20)^{* *}$ \\
$>6$ & $1.86(1.65-2.11)^{* *}$ & $1.38(1.24-1.53)^{* *}$ \\
Sleep hours/day & & \\
less than 7 & $0.83(0.71-0.97)^{*}$ & $0.84(0.73-0.95)^{*}$ \\
$>7$ to 8 & $1.00($ reference) & $1.00($ reference) \\
>8 & $0.78(0.71-0.85)^{* *}$ & $0.75(0.69-0.81)^{* *}$ \\
Pseudo R2 & 0.0834 & 0.1053 \\
Log Likelihood & -9707.8736 & $-12,629.694$
\end{tabular}

Notes: aOR-adjusted Odd Ratio, ${ }^{* *} p<0.01,{ }^{*} p<0.05$. Cl: confidence interval. Adjusted by age, education, household size, land tenure, employment status and other time use activities (active leisure, paid work, passive leisure \& personal activitie good health $(\mathrm{OR}=1.58 ; 95 \% \mathrm{CI}=1.43-1.74$ among men and $\mathrm{OR}=1.48 ; 95 \% \mathrm{CI}=1.30-1.68$ among women) $\mathrm{com}$ pared to those who devoted no time to these activities. Gardening and maintenance activities were associated with higher odds for good health. Older people who spent more than $120 \mathrm{~min} /$ day on these activities were more likely to report good health $(\mathrm{OR}=1.80 ; 95 \% \mathrm{CI}=1.64$ 1.98 among men and $\mathrm{OR}=1.56 ; 95 \% \mathrm{CI}=1.41-1.73$ among women) compared to those who did not allocate any time to these activities. The odds of reporting good health were significantly higher $(\mathrm{OR}=1.81 ; 95 \%$ $\mathrm{CI}=1.03-3.20$ among men and $\mathrm{OR}=2.46$; $95 \% \mathrm{CI}=1.63$ 3.72 among women) for elderly people who spent more than $120 \mathrm{~min} /$ day on childcare activities compared to those who devoted no time to childcare.

Furthermore, Table 3 shows that total productive housework activities and sleep duration were also related to health in both genders. In the model, we found a statistically significant association between good health and time devoted to housework. Elderly people who spent more than $6 \mathrm{~h}$ on housework activities had higher odds of reporting good health $(\mathrm{OR}=1.86 ; 95 \% \mathrm{CI}=1.65-2.11$ among men and $\mathrm{OR}=1.38 ; 95 \% \mathrm{CI}=1.24-1.53$ among women) compared to those who spent 1 to $3 \mathrm{~h}$ on these activities. The odds of reporting good health status were lower among older people who devoted less than $7 \mathrm{~h}$ $(\mathrm{OR}=0.83 ; 95 \% \mathrm{CI}=0.71-0.97 \mathrm{among}$ men and $\mathrm{OR}=$ $0.84 ; 95 \% \mathrm{CI}=0.73-0.95$ among women) and more than $8 \mathrm{~h}(\mathrm{OR}=0.78 ; 95 \% \mathrm{CI}=0.71-0.85$ among men and $\mathrm{OR}=$ 0.75 ; $95 \% \mathrm{CI}=0.69-0.81$ among women) compared to those who reported a sleep duration between 7 to $8 \mathrm{~h}$.

\section{Interactions}

Table 4 and Fig. 1a and b shows the combined associations of total housework hours and sleep duration on self-reported health by gender.

Among both genders, any combination of sleep duration not equal to 7-8 $\mathrm{h}$ and less than one hour spent on total housework was significantly associated with poorer health. On the other hand, the odds of reporting good health were significantly higher among older men who devoted more than $6 \mathrm{~h}$ /day of housework with any sleep hours category as compared to the reference group. Conversely, the odds of reporting good health were significantly lower among elderly women with any combination of sleep hours category with more hours of housework as compared to the reference group defined as above.

\section{Discussion}

This study explored the individual association between housework activities, sleep duration and self-reported health, and additionally examined the combined associations of total housework and sleep duration on selfreported health among elderly men and women in selected 
Table 4 Combined associations between good self-reported health status, total housework hours and sleep hours, pooled data of 7 countries. Men, women 65+ years old

\begin{tabular}{|c|c|c|c|}
\hline \multirow[t]{2}{*}{ Combinations } & Sleep $<7$ h/day & Sleep $>7$ to $8 \mathrm{~h} /$ day & Sleep $>8$ h/day \\
\hline & $\mathrm{aOR}(95 \% \mathrm{Cl})$ & aOR $(95 \% \mathrm{Cl})$ & $\mathrm{aOR}(95 \% \mathrm{Cl})$ \\
\hline \multicolumn{4}{|l|}{ Men } \\
\hline Housework <1 h/day & $0.72(0.52-1.00)^{*}$ & $1.04(0.81-1.34)$ & $0.61(0.51-0.73)^{* *}$ \\
\hline Housework 1 to $3 \mathrm{~h} /$ day & $0.92(0.67-1.26)$ & 1.00 (reference) & $0.86(0.72-1.03)$ \\
\hline Housework $>3$ to $6 \mathrm{~h} /$ day & $1.07(0.81-1.42)$ & $1.43(1.16-1.77)^{* *}$ & $1.06(0.88-1.27)$ \\
\hline Housework >6 h/day & $1.76(1.27-2.43)^{* *}$ & $1.68(1.32-2.15)^{* *}$ & $1.70(1.38-2.10)^{*}$ \\
\hline \multicolumn{4}{|l|}{ Women } \\
\hline Housework <1 h/day & $0.70(0.44-1.11)$ & $0.71(0.49-1.04)^{*}$ & $0.34(0.27-0.43)^{* *}$ \\
\hline Housework 1 to 3 h/day & $0.70(0.49-1.01)^{*}$ & 1.00 (reference) & $0.50(0.40-0.62)^{* *}$ \\
\hline Housework $>3$ to $6 \mathrm{~h} /$ day & $0.61(0.47-0.81)^{* *}$ & $0.75(0.60-0.94)^{*}$ & $0.60(0.49-0.74)^{* *}$ \\
\hline Housework >6 h/day & $0.77(0.59-1.01)^{*}$ & $0.91(0.72-1.14)$ & $0.78(0.62-0.97)^{*}$ \\
\hline
\end{tabular}

Notes: aOR-adjusted Odd Ratio, ${ }^{* *} p<0.01, * p<0.05$. Cl: confidence intervals. Adjusted by age, education, household size, land tenure, employment status and other time use activities (active leisure, paid work, passive leisure $\&$ personal activities)

high-income countries. As far as we know, this is the first study to analyze these interactive associations among elderly men and women in six European countries and the US using time use data. On the descriptive level, our study showed that elderly women allocate more time to routine and repetitive housework such as cleaning and cooking, whereas elderly men tend to devote more time to occasional tasks such as gardening and maintenance. Interestingly, both routine and occasional housework activities were positively associated with health among elderly men and women, but the magnitude of the association varied.
Regarding time spent on total housework activities, there were gender and cross-country differences. Women spent more time than men in housework activities, consistent with previous literature $[11,12]$. However, we observed a cross-country variation in time devoted to these activities. The result as shown in Additional file 2: Table S1 revealed that elderly women in the southern European countries and Germany allocated most time to total housework activities. In contrast, men's total housework activities were about $2 \mathrm{~h}$ per day less than that of women in the southern European countries. Meanwhile, the difference

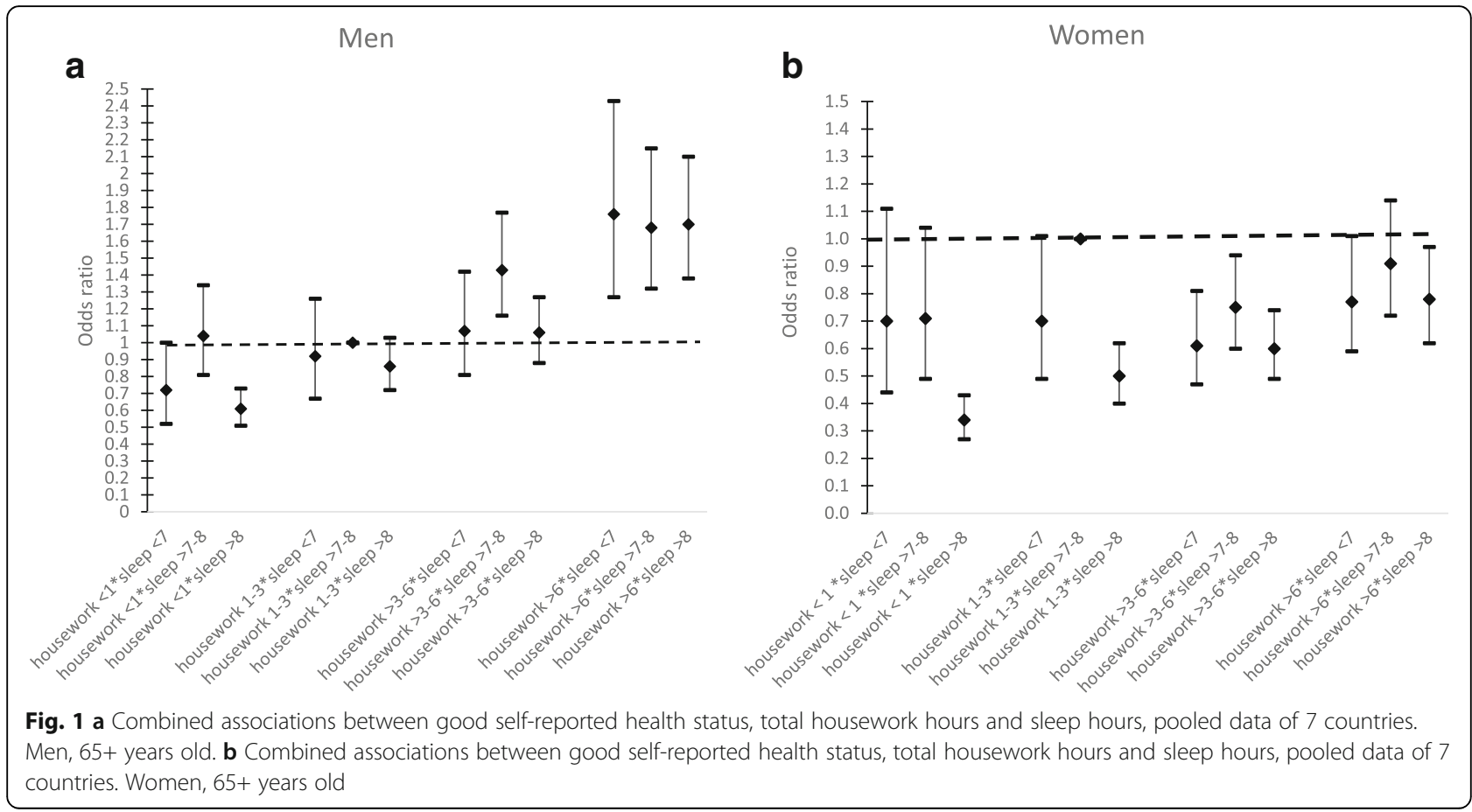


in housework among older men and women was approximately $1 \mathrm{~h}$ per day in Germany. Gender differences in the allocation of time especially for housework may to some extent be explained by cultural and social norms [34]. These norms may shape total work distribution and time use patterns of the various task of life among men and women. For instance, in the southern European countries where gender roles are still shaped in a more traditional way [34], women devote a significant amount of time to housework activities while the amount of time devoted to other time use activities may be reduced.

\section{Housework activities, sleep hours and health}

Although gender inequality in time allocation to housework activities exists $[15,16]$, we found that time devoted to the three broad categories of housework activities were positively associated with health among elderly women and men. Our findings of the association between routine housework activities (cleaning, cooking and shopping) and health contrast with a recent study conducted in China. Wen et al. [26] found no significant association of cooking, cleaning and grocery shopping and health among older men, but washing clothes and house cleaning were negatively associated with health among women. Meanwhile, our results corroborate a longitudinal study of 2761 older Americans aged 65 years [35]. Glass et al. [35] found productive housework activities such as cooking, shopping and gardening to be associated with lower risk of mortality. To these effects, we note that the three broad categories of housework activities involve some form of physical activities which may be beneficial to health among older adults [36]. Gardening and maintenance activities may increase fitness level and muscle strength because they require some form of physical exertion such as carrying equipment for repair works, lawn mowing, shoveling, digging holes and carrying soil. Previous studies have also stressed the health benefits of gardening for older adults; such benefits include physical health, psychological health, cognitive ability, and low risk of depression [37, 38]. Park et al. [39] recently reported that gardening has a positive effect on the blood lipid profiles, blood pressure and level of inflammatory markers in blood.

We also found a positive association between childcare and health status among older people. Although the amount of time devoted to childcare activities among the elderly is very small compared to young adults [6], caregiving support, especially caring for grandchildren, has been linked with good psychosocial health [40, 41]. $\mathrm{Ku}$ et al. [41] found that grandparenting was positively associated with good self-reported health and lower risk of depression. However, in some instances, more time devoted to childcare among older adults may have a negative impact on their physical or mental health [42], especially among custodial grandparents [43, 44].
Regarding time devoted to total housework hours, the result showed a positive association with health status among both genders. The few studies that examined the effects of total time spent on housework and health among elderly men have given inconsistent results $[26,35$, 45, 46]. Lawlor et al. [46] reported that heavy housework was not associated with reduced likelihood of being overweight among British women aged 60 to 79 years.

Among the working population, unequal division of household labor has been linked with adverse health outcomes especially among women $[19,21]$. One main hypothesis that has been advanced to explain these gender-specific inequalities in health is the "double burden" of work hypothesis. It has been postulated that the combination of paid market work and domestic work may be more stressful for women than men [47], which may affect women's health negatively $[19,48]$. Research findings $[6,34]$ indicate that the patterns and distribution of time use vary largely among the elderly and the working population. Therefore, the elderly may not have the same time constraints of combining both paid work and household activities like the working-age adults. In this case, the "double burden" of work hypothesis might lose its premise in explaining the effect of total housework on health among elderly men and women. In our view, housework activities by the older population can be perceived as domestic leisure activities [12] and forms of domestic physical activities [38] rather than "work overload", given a changed time availability after retirement. Hence, there is overall evidence for a positive association between housework activities and health status among elderly men and women.

Regarding sleep duration and self-reported health, we found a U-shaped association where both short $(<7 \mathrm{~h})$ and long $(>8 \mathrm{~h}$ ) sleep duration were negatively associated with self-reported health for both genders, consistent with prior findings [49-52]. The magnitude of the association was greater for long in comparison with short sleep duration. No significant difference in sleep duration was found between men and women within-countries, but there were cross-national variations (Additional file 2: Table S1). Currently, it is unclear whether older men or older women actually sleep longer on average [53-55]. Nevertheless, both elderly men and women allocate more time to sleep than any other time use activity $[6,24]$. This time use pattern is expected among older individuals due to the increasing incidence of adverse health conditions [6]. Conversely, both short and long sleep duration have been found to be associated with adverse health outcomes including diabetes mellitus [55, 56] obesity [57, 58], osteoporosis [59] and hypertension [60]. Furthermore, recent studies suggest that both short and long sleep duration are associated with increased mortality rates [23, 61]. Considering gender, a cohort study by Ikehara et al. [62] showed a U-shaped 
association between sleep duration and all-cause mortality for both men and women. Even though our data does not permit examining the association with mortality, previous studies have consistently shown a strong relationship between self-reported health and mortality [63, 64].

While the assessment of gender differences in housework and sleep duration with health status was informative, our study further examined the combined associations, as they provide information about a potentially important interactive gender effect. The results showed that the interactive associations between housework, sleep duration and selfreported health vary by gender. Among men, the combination of longest housework hours with either short or long sleep duration yielded a strong positive association with self-reported health. On the contrary, a combination of longest housework hours with either short or long sleep duration yielded a negative association on self-reported health among women. The result suggests that regardless of sleep duration, less housework was associated with poor health status among both genders.

There is no prior evidence of the combined association of sleep duration and time devoted to housework on health status. Nonetheless, Kiosses and Alexopoulos [65] found that older adults who report higher levels of depression devote less time to housework and other instrumental activities of daily living (IADL) such as shopping and meal preparation. This negative association can be explained by little or no physical or mental energy associated with less housework, as physical inactivity has been found to play a significant role in the development of chronic diseases [66]. As discussed above, short and long sleep durations have also been linked to poor health $[55,56]$, therefore our findings of the combined effects may be attributed to the negative correlations between less housework, poor sleep and health. Regarding long housework hours and sleep duration, we observed a different pattern among both genders (Fig. 1a and b). For men, long hours of housework was associated with good health status regardless of sleep duration, whereas these very long hours of housework combined with either short or long sleep was negatively associated with health among women. In fact, these patterns suggest that long housework hours is less sensitive to elderly men's health [67] since the impact of long housework and health status appeared to be least influenced by sleep duration.

\section{Limitations and strengths}

Our study has some limitations. First, the cross-sectional design of the study prevents conclusions about causality because the association between sleep duration, housework hours and self-reported health may be reciprocal. Second, this study relied on subjective measures to assess duration of sleep, housework and health. However, time use estimates of daily activities have been found to be more accurate and reliable in time use surveys than survey estimates $[68,69]$. Notwithstanding, we acknowledge that sleep disturbance [70], may impinge on sleep quality and duration [71], but sleep quality cannot be assessed with time use surveys [24]. Thus, future research should explore objective and sophisticated time use data collection technologies such as smart-phone apps and actigraphy. Third, due to data availability and constrains, we used diary data of time use surveys that have been collected at different points in time with different modes of data collection in the chosen countries, but evaluation studies suggest that these differences do not affect the comparability of the data [11]. Despite these limitations, this current study provides an initial overview of housework activities, sleep duration and their correlations with self-reported health of the population aged $65+$ years using a large-scale, homogeneous and comparative set of time use data in Europe as well as the US.

\section{Conclusions}

We provide the first evidence of the associations between housework activities, sleep duration and selfreported health among older individuals in selected high-income countries. Our findings suggest that housework activities remain strongly gendered even after retirement. Our findings further suggest that even though time allocation to housework activities may be beneficial to the health among elderly men and women, women have higher odds of reporting poor health when more time is devoted total housework combined with either short or long sleep duration.

\section{Additional files}

Additional file 1: Table S2. General description of total housework and sleep hours ( means and SD), men and women, by country. (DOCX $15 \mathrm{~kb}$ )

Additional file 2: Table S1. Typology of activities. (DOCX 16 kb)

\section{Acknowledgments \\ The authors thank Prof. Dr. med. Hajo Zeeb, Dr. Ingeborg Jahn and Prof. Elisabeth Jonas for their useful comments and suggestions.}

Authors' contribution

NKA conceived the study, performed statistical analysis and drafted the manuscript. NKA and TB critically revised and reviewed the manuscript. All authors read and approved the final manuscript.

Funding

There was no funding source.

Availability of data and materials

The data used for this study comes from the Multinational Time Use Study (MTUS). Detailed information on the survey design and characteristics are provided on the MTUS homepage, https://www.timeuse.org/mtus

Ethics approval and consent to participate

The authors were granted approval from the Multinational Time Use Study Review Board to obtain and use the collected data for analysis. All data were anonymized prior to the authors receiving the data. 


\section{Consent for publication}

Not applicable

\section{Competing interests}

The authors declare that they have no competing interests.

\section{Publisher's Note}

Springer Nature remains neutral with regard to jurisdictional claims in published maps and institutional affiliations.

\section{Received: 29 May 2017 Accepted: 5 December 2017} Published online: 11 January 2018

\section{References}

1. Grapsa E, Posel D. Sequencing the real time of the elderly: evidence from South Africa. Demogr Res. 2016;35:711-44.

2. Cornwell B, Laumann EO, Schumm LP. The social connectedness of older adults: a National Profile. Am Sociol Rev. 2008;73:185-203.

3. Einolf $\mathrm{CJ}$. Will the boomers volunteer during retirement? Comparing the baby boom, silent, and long civic cohorts. Nonprofit Volunt Sect Q. 2009:38:181-99.

4. Musick MA, Herzog AR, House JS. Volunteering and mortality among older adults: findings from a national sample. J Gerontol Ser B Psychol Sci Soc Sci. 1999:54:S173-80

5. Zimmer Z, Lin H-S. Leisure activity and well-being among the elderly in Taiwan: testing hypotheses in an Asian setting. Journal of Cross-Cultural Gerontology. 1996;11:167-86.

6. Gauthier AH, Smeeding TM. Time use at older ages cross-National Differences. Research on Aging. 2003;25:247-74.

7. Cardia E, Ng S. Intergenerational time transfers and childcare. Rev Econ Dyn 2003;6:431-54

8. Lumsdaine RL, Vermeer SJC. Retirement Timing of Women and the Role of Care Responsibilities for Grandchildren. National Bureau of Economic Research. 2014;20756:20756.

9. Krantz-Kent R, Stewart J. How do older Americans spend their time. Monthly Lab Rev. 2007:130:8

10. Wilson J. Volunteering. Annu Rev Sociol. 2000;26:215-40.

11. Robinson J, Godbey G Time for life: the surprising ways Americans use their time: Penn State press.(2010)

12. Leitner MJ. Leitner SF. Leisure in later life: Haworth Press New York: 2004

13. Szinovacz ME. Changes in housework after retirement: a panel analysis. J Marriage Fam. 2000;62:78-92.

14. Adjei NK, Brand T, Zeeb H. Gender inequality in self-reported health among the elderly in contemporary welfare countries: a cross-country analysis of time use activities, socioeconomic positions and family characteristics. PLoS One. 2017;12:e0184676

15. Bianchi SM, Sayer LC, Milkie MA, Robinson JP. Housework: who did, does or will do it, and how much does it matter? Social Forces. 2012;91:55-63.

16. Sayer LC. Trends in Women's and Men's time use, 1965-2012: back to the future? Gender and Couple Relationships: Springer; 2016. p. 43-77

17. Coltrane $\mathrm{S}$. Research on household labor: modeling and measuring the social embeddedness of routine family work. J Marriage Fam. 2000;62:1208-33.

18. Barnett RC, Shen Y-C. Gender, high-and low-schedule-control housework tasks, and psychological distress a study of dual-earner couples. J Fam Issues. 1997;18:403-28

19. Bird CE. Gender, household labor, and psychological distress: the impact of the amount and division of housework. J Health Soc Behav. 1999:32-45.

20. Glass J, Fujimoto T. Housework, paid work, and depression among husbands and wives. J Health Soc Behav. 1994:179-91.

21. Bird CE, Fremont AM. Gender, time use, and health. J Health Soc Behav. 1991;32:114-29.

22. Everard KM, Lach HW, Fisher EB, Baum MC. Relationship of activity and social support to the functional health of older adults. J Gerontol Ser B Psychol Sci Soc Sci. 2000;55:S208-12.

23. Gallicchio L, Kalesan B. Sleep duration and mortality: a systematic review and meta-analysis. J Sleep Res. 2009;18:148-58.

24. Chatzitheochari S, Arber S. Lack of sleep, work and the long hours culture: evidence from the UK time use survey. Work, Employment \& Society. 2009 23:30-48.

25. Grandner MA, Patel NP, Gehrman PR, Perlis ML, Pack Al. Problems associated with short sleep: bridging the gap between laboratory and epidemiological studies. Sleep Med Rev. 2010;14:239-47.
26. Wen X, Liang Y, Zhu J, Wu T. The effects of housework on the health of retired older adults: a preliminary investigation from the Tongji-Dongfeng cohort study, China. PLoS One. 2013;8:e57232.

27. Fisher K, Gershuny J, Gauthier A Multinational time use study-User's guide and documentation (2012).

28. Klumb PL, Baltes MM. Time use of old and very old Berliners: productive and consumptive activities as functions of resources. J Gerontol Ser B Psychol Sci Soc Sci. 1999;54:S271-8.

29. Reid MG Economics of household production (1934).

30. da Silva AA, de Mello RGB, Schaan CW, Fuchs FD, Redline S, et al. Sleep duration and mortality in the elderly: a systematic review with metaanalysis. BMJ Open. 2016;6:e008119.

31. Idler EL, Benyamini Y. Self-rated health and mortality: a review of twentyseven community studies. J Health Soc Behav. 1997;38:21-37.

32. DeSalvo KB, Bloser N, Reynolds K, He J, Muntner P. Mortality prediction with a single general self-rated health question. J Gen Intern Med. 2006;21:267-75.

33. StataCorp Stata 14 base reference manual. College Station, TX: Stata Press (2015).

34. Anxo D, Flood L, Mencarini L, Pailhé A, Solaz A, et al. Time allocation between work and family over the life-cycle: a comparative gender analysis of Italy. Sweden and the United States: France; 2007.

35. Glass TA, de Leon CM, Marottoli RA, Berkman LF. Population based study of social and productive activities as predictors of survival among elderly Americans. BMJ. 1999:319:478-83.

36. Walsh JM, Rogot Pressman A, Cauley JA, Browner WS. Predictors of physical activity in community-dwelling elderly white women. J Gen Intern Med. 2001;16:721-7.

37. Park S-A, Shoemaker CA, Haub MD. Physical and psychological health conditions of older adults classified as gardeners or nongardeners. Hortscience. 2009:44:206-10.

38. Park S-A, Lee A-Y, Son K-C, Lee W-L, Kim D-S. Gardening intervention for physical and psychological health benefits in elderly women at community centers. HortTechnology. 2016;26:474-83.

39. Park S-A, Lee A-Y, Park H-G, Son K-C, Kim D-S, et al. Gardening intervention as a low-to moderate-intensity physical activity for improving blood lipid profiles, blood pressure, inflammation, and oxidative stress in women over the age of 70: a pilot study. Hortscience. 2017;52:200-5.

40. Grundy EM, Albala C, Allen E, Dangour AD, Elbourne D, et al. Grandparenting and psychosocial health among older Chileans: a longitudinal analysis. Aging Ment Health. 2012;16:1047-57.

41. Ku L-JE, Stearns SC, Van Houtven CH, Lee S-YD, Dilworth-Anderson P, et al Impact of caring for grandchildren on the health of grandparents in Taiwan. J Gerontol Ser B Psychol Sci Soc Sci. 2013;68:1009-21.

42. Hayslip B, Kaminski PL. Grandparents raising their grandchildren: a review of the literature and suggestions for practice. The Gerontologist. 2005;45:262-9.

43. Hadfield JC. The health of grandparents raising grandchildren: a literature review. I Gerontol Nurs. 2014:40:32-42.

44. Blustein J, Chan S, Guanais FC. Elevated depressive symptoms among caregiving grandparents. Health Serv Res. 2004:39:1671-90.

45. Borrell C, Muntaner C, Benach J, La A. Social class and self-reported health status among men and women: what is the role of work organisation, household material standards and household labour? Soc Sci Med. 2004;58:1869-87.

46. Lawlor D, Taylor M, Bedford C, Ebrahim S. Is housework good for health? Levels of physical activity and factors associated with activity in elderly women. Results from the British Women's heart and health study. J Epidemiol Community Health. 2002;56:473-8.

47. Bratberg E, Dahl SÅ, Risa AE. The double burden': do combinations of career and family obligations increase sickness absence among women? Eur Sociol Rev. 2002;18:233-49.

48. Hunt K, Annandale E. Just the job? Is the relationship between health and domestic and paid work gender-specific? Sociology of Health \& IIIness. 1993;15:632-64.

49. Kim J-H, Kim KR, Cho KH, Yoo K-B, Kwon JA, et al. The association between sleep duration and self-rated health in the Korean general population. Journal of clinical sleep medicine: JCSM: official publication of the American Academy of Sleep Medicine. 2013;9:1057.

50. Frange C, de Queiroz SS, da Silva Prado JM, Tufik S, de Mello MT. The impact of sleep duration on self-rated health. Sleep Sci. 2014;7:107-13.

51. Shankar A, Charumathi S, Kalidindi S. Sleep duration and self-rated health: the national health interview survey 2008. Sleep. 2011:34:1173-7.

52. Magee CA, Caputi $P$, Iverson DC. Relationships between self-rated health, quality of life and sleep duration in middle aged and elderly Australians. Sleep Med. 2011;12:346-50. 
53. Ohayon MM. Interactions between sleep normative data and sociocultural characteristics in the elderly. J Psychosom Res. 2004;56:479-86.

54. Tamakoshi A, Ohno Y. Self-reported sleep duration as a predictor of allcause mortality: results from the JACC study, Japan. SLEEP-NEW YORK THEN WESTCHESTER. 2004;27:51-4.

55. Cappuccio FP, D'elia L, Strazzullo P, Miller MA. Quantity and quality of sleep and incidence of type 2 diabetes. Diabetes Care. 2010;33:414-20.

56. Gottlieb DJ, Punjabi NM, Newman AB, Resnick HE, Redline S, et al. Association of sleep time with diabetes mellitus and impaired glucose tolerance. Arch Intern Med. 2005;165:863-7.

57. Cappuccio FP, Taggart FM, Kandala N, Currie A, Peile E, et al. Meta-analysis of short sleep duration and obesity in children and adults. SLEEP-NEW YORK THEN WESTCHESTER. 2008;31:619.

58. Gangwisch JE, Malaspina D, Boden-Albala B, Heymsfield SB. Inadequate sleep as a risk factor for obesity: analyses of the NHANES I. SLEEP-NEW YORK THEN WESTCHESTER. 2005;28:1289.

59. Lima MG, Francisco PMSB, de Azevedo Barros MB. Sleep duration pattern and chronic diseases in Brazilian adults (ISACAMP, 2008/09). Sleep Med. 2012;13:139-44.

60. Nagai M, Hoshide S, Kario K. Sleep duration as a risk factor for cardiovascular disease-a review of the recent literature. Curr Cardiol Rev. 2010;6:54-61.

61. Cappuccio FP, D'Elia L, Strazzullo P, Miller MA. Sleep duration and all-cause mortality: a systematic review and meta-analysis of prospective studies. Sleep. 2010;33:585.

62. Ikehara S, Iso H, Date C, Kikuchi S, Watanabe Y, et al. Association of sleep duration with mortality from cardiovascular disease and other causes for Japanese men and wom-en: the JACC study. Sleep. 2009;32:259-301.

63. Schnittker J, Bacak V. The increasing predictive validity of self-rated health. PLoS One. 2014;9:e84933.

64. Zhao J, Yiengprugsawan V, Seubsman S-a, Kelly M, Bain C, et al. Selfreported health and subsequent mortality: an analysis of 767 deaths from a large Thai cohort study. BMC Public Health. 2014;14:860.

65. Kiosses DN, Alexopoulos GS. IADL functions, cognitive deficits, and severity of depression: a preliminary study. Am J Geriatr Psychiatry. 2005;13:244-9.

66. Warburton DE, Nicol CW, Bredin SS. Health benefits of physical activity: the evidence. Can Med Assoc J. 2006;174:801-9.

67. Geist C, Tabler J. Somebody has to DUST! Gender, health, and housework in older couples. Journal of Women \& Aging. 2017:1-11.

68. Bonke J. Paid work and unpaid work: diary information versus questionnaire information. Soc Indic Res. 2005;70:349-68.

69. Kan MY, Pudney S. Measurement error in stylized and diary data on time use. Sociol Methodol. 2008;38:101-32

70. Lee M, Choh A, Demerath E, Knutson K, Duren D, et al. Sleep disturbance in relation to health-related quality of life in adults: the Fels longitudinal study. J Nutr Health Aging. 2009;13:576-83.

71. Kumari M, Green R, Nazroo J. Sleep duration and sleep disturbance. Financial circumstances, health and well-being of the older population in England: the. 2008:178-226.

\section{Submit your next manuscript to BioMed Central and we will help you at every step:}

- We accept pre-submission inquiries

- Our selector tool helps you to find the most relevant journal

- We provide round the clock customer support

- Convenient online submission

- Thorough peer review

- Inclusion in PubMed and all major indexing services

- Maximum visibility for your research

Submit your manuscript at www.biomedcentral.com/submit 